\title{
APONTAMENTOS PARA O ESTUDO DO PONTO DE VISTA DA MERCADORIA NA LITERATURA BRASILEIRA
}

\section{Luiz Dagobert de Aguirra Roncari (USP)}

Para uma antiga colônia que alcançou a independência sem grandes lutas, como foi o caso do Brasil. o processo de formulação de uma identidade nacional adquiriu algumas particularidades com relação à forma como ele se deu em outras regiões coloniais e entre as próprias nações européias. O objetivo deste trabalho ${ }^{(*)}$ é o de tentar mostrar como a literatura, no Brasil, participou desse processo muito de perto e colaborou com ele na produção de uma simbologia e de uma mitologia que o justificavam. Isso, em alguns momentos, porém. em outros, serviu também para fazer a sua critica e procurou revelar sobre que bases questionáveis e relações deformantes ele se sustentava. Esse fato foi mais ou menos generalizado no ex-mundo colonial, pela importância que teve a literatura até meados do século XX. mas adquiriu contornos próprios em cada região onde se deu. Antes de tudo, devemos dizer que a literatura oscilou no Brasil entre assumir essa tarefa de colaborar na construção da nova identidade nacional, voltando-se programaticamente para a afirmação e promoção das suas características intrínsecas: e apreciar em profundidade o sentido e os efeıtos da "modernização" dos costumes matcriais e espirituais, que nada mais eram do que os da nova forma de integração da recém-inaugurada vida nacional no sistema capitalista (ou de comércio) internacional - e no que se convencionou chamar de neocolonialismo, sob a égide européia, primeiro, e americana. depois. O que está por trás de tudo isso, como o seu pano de lundo, é a passagem de uma sociedade colonial, escravista e patriarcal, como a brasileira (sem se esquecer que esteve desde o início integrada a um modemo sistema de trocas mercantis internacional, porém internamente dominada por valores tradicionais, católicos, monárquicos e aristocráticos). para uma sociedade burguesa.

A primeira versão deste trabalho foi escrita para ser apresentada no $\mathrm{X}$ Congresso da FIEALC, em Moscou, em junho de 2001. 
com uma nova mentalidade melhor ajustada a ela, tendo a produção de mercadorias e o capital como a forma dominante de riqueza. Porém, o foco da reflexão e o que nos interessa aqui é apreciar a capacidade que teve a literatura para captar e fixar a forma específica desse trânsito o que se tornou posteriormente um trabalho do historiador, liberando-a para concentrar-se apenas na apreciação em profundidade de como ele foi humana e socialmente vivido. Entre nós, a literatura pôde voltar a sua atenção para observar como aquilo que era apresentado como universal, a realidade e o valores da vida burguesa -- que entre nós aparecia como o "moderno", em contraste com o que se vivia na antiga colônia, o "atrasado" - . no Brasil se particularizava, na medida em que o que era tido como particular e traço de cultura, o que se convencionou chamar de "a cordialidade brasileira". os valores familiares patriarcais, resistia à força universalizante, principalmente às Idéias liberais e democráticas.

Como complemento disso, da relação complexa entre o moderno e o arcaico, o nacionalismo e o liberalismo (reconhecimento de uma identidade e de um contexto próprios e comunhão ideológica e comercial) apresentaram-se não só como ideários com orientações distintas e conflitantes, mas também como imperativos para a sobrevivência das novas formações nacionais: tanto deveríamos saber resistir às pressões comerciais e politicas externas, como era vital para a sobrevivência enquanto nação a integração comercial e financeira. A literatura participou nào só reflexivamente como também ativamente das tensões e discussões geradas por essas duas forças ideológicas, em que os homens procuravam as soluções para os novos problemas que enfrentavam, dividindo-se numa ou noutra dıreção: na da afirmação de uma identidade própria, apoiada na valorização da sua realidade particular, ou na da modernização rápida, abrındo-se para o comércio e adotando os valores universais do novo ideário liberal. Não se pode dizer que as nações centrais européias e os próprios EUA estiveram livres dessas tensões, ao contrário, elas estiveram no centro mesmo das duas Grandes Guerras. Mas. no mundo das ex-colônias ou da periferia, elas eram acrescidas de uma dificuldade: tanto o nacionalismo particularista como o liberalismo universalista eram totalmente estranhos ao seu passado tribal. comunal, colonial e escravista das casas-grandes: o velho com o qual o novo se confrontava não vinha de uma realidade feudal (trabalho servil e sociedade aristocrática) e monárquica, ele era escravista e colonial 
(além de indigena, marginalmente). Portanto. os ideários nacional. liberal e democrático encontraram aqui um terreno simbólico, cultural. juridico-institucional e material bastante distinto, reagindo muitas vezes como obstáculo intransponivel para os novos valores. Pelo lado da politica e da organização do Estado, as dificuldades enfrentadas eram as de como compatibilizar um ideário e uma simbologia homogênea nacional com o pragmatismo da dominação dos poderes regionais e locais caudilhistas. E. pelo lado econômico-jurídico universalista, as dificuldades eram de como se fazer valer a liberdade individual e a cidadania com o escravismo e outros tipos de servidões e diferenciações raciais e sociais. A dralética entre o novo (institucional e ideológico) e o velho (a realidade crua dos fatos, as relações de dominação) veio a se constituir talvez no mass importante problema a ser estudado pela nossa historiografia. O novo dificilmente poderia se implantar sem a superação em profundidade do velho: ao contrário do que se deu. com um trânsito suave e cheio de compromissos, no qual se carregava muito do velho para a nova realidade, a ponto de transformá-la numa cobertura de antigas estruturas que resistiam. Foi assim que a literatura a representou, entre outras, a de Machado de Assis: como esse novo era ao mesmo tempo velho, antigas estruturas cobertas por uma nova roupagem.

Desde o romantismo foram colocadas para a literatura brasileira duas perspectivas: uma, ideológica, que correspondia também às aspirações da politica do Estado, de afirmação da nova simbologia nacional, interessada inclusive no resgate e na construção de uma tradição que fundamentasse e desse consistência histórica à organização da nova nação e da sua identidade; e outra critica, que tinha com a verdade literária o seu maior compromisso, como o de apreciar os efeitos da modernização, os novos termos da condição da vida na história, à medida que a literatura rompia com os cânones clássicos. Isto não quer dizer que podemos logo classificar os autores segundo a opção que fizeram por uma ou outra perspectiva e se alinharam a elas, e que essa opção tivesse determinado a qualidade das suas obras. Alguns autores tiveram um pé em cada uma, como José de Alencar, autor ao mesmo tempo de O Guarani e Iracema e de Senhora e Luciola: outros, que participaram como poucos da claboração e promoção do indianismo e da busca de uma literatura americana, como Gonçalves Dlas, um autor decisivo para a constituição de um novo ponto de vista para a literatura brasileira. 
Nos seus Primeiros Cantos, aproveitando-se do que a literatura européia tinha de melhor e mais novo, procurou reescrever, a partir da visão do índio e da colônia, o quanto foi também destrutivo o sentido da colonização européia: "Vem trazer-vos algemas pesadas", "Mesmo o Piaga inda escravo há de ser". Com isso, ele procurava dizer o que tinha significado, da perspectiva do homem da terra, a colonização, até então só apreciada pelas elites como cristianizadora e civilizadora.

Essas duas perspectivas não se apresentaram logo de início como definidas e dividindo os autores entre uma e outra, ao contrário, elas apareceram misturadas e só lentamente foram se separando, tornando muitas vezes a se misturarem e a se separarem, oscilando $\mathrm{com}$ as conjunturas nacionais e internacionais. No processo de constituição de um ponto de vista critico na literatura brasileira, Machado de Assis foi um marco, não só na sua constituição, como também na forma da sua realização. Simuladamente, sem deixar o leitor da época chocar-se com o fato de que era ele próprio e não um outro que estava sendo ali representado, mais nas suas misérias do que nas suas virtudes, porém com essas misérias encobertas sempre por um véu de compreensão afetuosa e simpática, tendo as suas brutalidades apresentadas como se fossem peraltices de meninos traquinas, ele fez-se admirar por eles enquanto autor, com uma atração parecida à que exerce o carrasco sobre a sua vitima. Também não queremos dizer que a partir de Machado as águas tenham se separado e esse ponto de vista novo, consolidado. Iniciado com José de Alencar, completa-se com Machado o que poderíamos chamar de $\mathrm{um}$ ponto de vista da mercadoria, só que, com eles, era um ponto de vista novo, cuja implantação e vigência o autor apreciava no plano das personagens, as quais oscilavam entre os valores da tradição, familiares e patriarcais, e os novos, os mercantis e do interesse (o que se pode ganhar em termos de riqueza, prestígio e poder a partir de cada gesto e de cada afeto). Já com Machado, sobrava para o autor apreciar a comédia com o riso da melancolia, aquele de quem não via outra saída a não ser um pequeno fundo de esperança, como o depositado "na mocidade", pelo comendador Aires, reconhecendo neles o direito de "separar-se alegremente do extinto e do caduco". dos mortos e dos velhos, mas para cair em mãos incertas e, possivelmente, não menos tenebrosas. A transição de Alencar para Machado é a da personagem para o meio social: o que, em Alencar. era uma característica censurável e até repulsiva de alguns indivíduos 
e algumas personagens, a de apreciar o mundo e agir a partir do ponto de vista do interesse mercantil, em Machado já é um valor social dominante e assimilado, não causa mais estranheza, apenas é encoberto por um verniz ideológico e de civilidade, para tornar satisfatória a convivência social: alguns podem agir por capricho e abusar da sua posição, porque já têm fortuna, geralmente herdada da velha acumulação senhorial escravista; outros, são obrigados a agir por interesse, porque não a têm ou já a têm e querem mais, o que os leva à submissão, subserviência e perda dos valores e caráter; nessa assimetria, ninguém escapava nem se salvava, todos se deformavam enquanto sujeitos.

Porém. a história da literatura num país de estrutura colonial rígida e definições de personalidade tênues ilustra muito bem como as forças regressivas renascem a cada novo ciclo e têm de ser novamente enfrentadas. Mário de Andrade, em particular, e os modernistas, em geral, voltam a oscilar entre o olhar afetuoso do país, tomado de simpatia pelo particular, e o crítico da voragem de um capital que não é contido pelos freios civilizatórios. Toda a obra de Mário, Macunaima, Contos Novos e as poesias, tanto tem um olhar afetivo e simpático para com as tradições populares do país, aquilo que ele via como a nossa "solaridade", como se imbui de uma crítica profunda das deformações da sua estrutura social. Um conto como "O poço", de Contos Novos, é uma das representações mais radicais das novasvelhas relações de classe, modernizadas com a expansão do café e a libertação da escravidão no Oeste de São Paulo. O que tinha sido abolido legalmente, permanecia vivíssimo na cabeça de todos.

Os anos 30 foram fundamentais para a distinção entre essas duas perspectivas, embora, em muitos autores elas continuassem ainda misturadas. Tomemos só o exemplo de Jorge Amado, pois nele o pitoresco e o crítico se combinam como dois artificios, criando uma literatura, de certa forma, constituída por dois exageros. Ora ele deixase levar pelo pitoresco popular e patriarcal, ora o seu texto se aproxima do discurso crítico e panfletário. Mas não é só ele. Érico Veríssimo, José Lins do Rego e outros não conseguem evitar as atrações do público leitor, formado e estimulado por um gosto de corte regionalista e nacionalista, em detrimento do compromisso com a investigação dos movimentos mais profundos vividos pelos sujeitos no processo histórico. Os solavancos em termos de estragos sociais que produziam os ciclos econômicos vividos na periferia, decorrentes 
dos ajustes e das modificações ocorridas no cenário comercial internacional, agora, na década de 30 , tornou a literatura muito sensivel a essas mudanças e aguçou o seu olhar documental. A observação e a crítica dos movimentos mais dolorosos em termos sociais, como os da seca, do coronelismo, das migrações internas, das doenças e da fome, e mais visíveis e aparentes, desviaram muitas vezes a atenção do que se passava nas camadas mais profundas do sujeito na sua vivência histórica. Estar atento a isto, à rotina do cotidiano e da reificação que se aprofundava a cada passo com a "modernização" do país, seria abdicar da exceção e do politicamente solúvel, além de mais impactante para a comoção imediata do leitor. Poucos foram os que se detiveram no movimento corrosivo que se dava no dia-a-dia e do qual não escapava ninguém. O fantástico da periferia era mais atrativo pelas proporções grotescas que as deformações adquiriam, assim, os traços expressionistas foram talvez os mais marcantes da estética desse tempo, representados com linhas fortes, sem meios tons nem muitas velaturas ideológicas. Tudo se passava diretamente e através de ações explicitas. Mário de Andrade, Oswald de Andrade, Carlos Drummond, Dionélio Machado e Graciliano Ramos foram talvez os que mais se deram conta disso. Guimarães Rosa foi o último que, recusando-se a qualquer tipo de mistificação, embutiu numa literatura de aparências míticas e fantásticas uma alegoria do nosso processo histórico: o triste trânsito de uma realidade patriarcal para o mundo burguês da mercadoria, dominado por uma nova forma de encanto, só que, desta vez, um engano destrutivo e mortal: o fetiche da mercadoria. Isto está magnificamente representado num dos romances de Corpo de Baile, na "Estória de Lélio e Lina", que tem um fïm duplo: a Jiní, a mulata escura de olhos verdes, como a personificação do próprio fetiche da mercadoria, ganhando autonomia e saindo da realidade patriarcal do Pinhém e indo reinar senhora "dona e mandona", no seu novo reino da história, o "Estrezado", o lugar do cansaço, do trabalho e dos dias que esgotam a vida do homem; e o milagre do encontro e reunião impossivel do Sol com a Lua, de Lélio e Lina. Só que agora o ponto de vista da mercadoria não está apenas encarnado num ou noutro personagem ou como o valor reinante no meio social; ele aparece como uma espécie de fatalidade e condenação, de doença dum tempo corrosivo, mas a que ainda se pode resistir, só que através de outras alianças, da reza e do milagre. $\dot{E}$ isto que faz do sertão um lugar ambíguo para Guimarães Rosa: embora esteja sempre ameaçado pela 
desordem e pelo informe, por um lado, e pela ambigüidade da mercadoria, por outro, nele ainda é possível o milagre. Foi o último, talvez, que, diante da modernização que vinha e se anunciava, acreditava que ainda pudesse haver uma tábua de salvação, ainda que milagrosa'.

O golpe militar de 1964 e os atos institucionais pós-68 tiveram implicações profundas na vida cultural do país: a desorganização de muitas das já poucas instituições culturais existentes, devido a proibições, censura, cortes de verbas, empastelamentos, perseguições e outros meios ainda mais violentos; a infantilização do povo, com a decretação da sua irresponsabilidade política e constitucional; a promoção da indústria cultural e a liberação aos meios de comunicação, principalmente às redes de televisão (veículo, no Brasil, de sustentação essencialmente publicitária), do poder de formação e de manipulação da opinião; o debilitamento do sistema de ensino público básico e médio, com o desmantelamento, na prática, do antigo corpo de professores; e a fragilização do ensino universitário, com as cassações e aposentadorias de professores, muitas das suas melhores formações. Os resultados disso, que significou a retomada de um processo de estratificação e elitização social e cultural, que havia sido um tanto quanto revertido com as políticas sociais e culturais pósrevolução de 30 , repercutiram também gravemente na nossa literatura. $\mathrm{O}$ escritor, que tinha a pretensão de um dia vir a ser adotado pelo povo, pelo leitor - as políticas culturais e educacionais do período chamado de nacional-desenvolvimentismo, de alguma forma, propunham-se a criar uma ponte entre o escritor e o povo, aproximando um do outro -, agora, passaria a visar principalmente o consumidor, sendo intermediado pela empresa comercial e publicitária. O escritor (poeta, romancista, cronista, dramaturgo), até então, buscara na literatura não tanto uma fonte de renda, o que era quase impensável, a não ser para alguns poucos, como Jorge Amado e Erico Veríssimo, por exemplo². Ele era na maior parte funcionário

Sobre o assunto, ver o ensaio de minha autoria "Irmão Lélio, irmã Lina: incesto e milagre na 'ilha do Pinhém'", in Estudos Avançados, 42, revista do IEA/USP, maio-agosto de 2001.

2 O que Mário de Andrade escreve numa carta a Manuel Bandeira é ilustrativo do que procurava o autor com o livro, ainda no final da década de 20. Para ele, o atrativo do ganho econômico é visto ainda com uma certa censura. Para expressá-lo, ele usa o termo gadanhar em vez de 
público, diplomata, professor ou então profissional liberal, médico, advogado, jornalista, que procurava na literatura mais a confirmação do próprio talento e, com isto, o reconhecimento e o prestígio, do que fazer dela uma fonte de renda ${ }^{3}$. Foi no oco do chamado "vazio cultural", da década de 70 , que a literatura tendeu a tornar-se num meio de busca do sucesso e, com ele, do best-seller e a sua transformação numa atividade razoavelmente lucrativa. Isso não quer dizer que a mesma motivação não tenha havido antes, só que não tinha sido a dominante, como acontecia agora. A história da literatura

ganhar, termo que vem de gadanho, garra de ave de rapina: "Mas meu caso agora é que o Ensaio [sobre a música brasileira] custa 6 contos a edição e careci de campear editor. Achei um na casa Chiarato que pelos elogios que tenho feito pra ela, justos, por estar editando as músicas de Mozart Camargo Guarnieri (mocico aparecendo, 21 anos, aluno de composição do Lamberto Baldi e bastante aconselhado por mim na orientação estética, sem ser aluno meu) a casa acho que ficou um bocado comovida e aceitou editar o Ensaio... eu não ganhando nem um vintém por essa edição de 1000 exemplares, tendo 15 exemplares pra mim, e me obrigando a entregar pra mesma casa meu Compêndio de História da Música!!! Não venha me passando pito porque é inútil, tá resolvido, tá feito e eu aceitei assim porque não é mesmo com o livro que pretendo gadanhar quatrini" Correspondência Mário de Andrade \& Manuel Bandeira, org. de Marco Antonio de Moraes, São Paulo, EDUSP, 2000, p. 400.

Numa crônica excelente tanto pelo seu valor literário quanto de apreciação histórica, Carlos Drummond de Andrade fala de como a literatura brasileira era uma "literatura de funcionários públicos" e de "literato funcionário", porém sem ver nisso nada de negativo, ao contrário. Ele diz: "O emprego do Estado concede com que viver, de ordinário sem folga, e essa é condição ideal para bom número de espíritos: certa mediania que elimina os cuidados imediatos, porém não abre perspectiva de ócio absoluto. $\mathrm{O}$ indivíduo tem apenas a calma necessária para refletir na mediocridade de uma vida que não conhece a fome nem o fausto; sente o peso dos regulamentos, que lhe compete observar ou fazer observar; o papel barra-lhe a vista dos objetos naturais, como uma cortina parda. É então que intervém-lhe a imaginação criadora, para fazer desse papel precisamente o veículo de fuga, sorte de tapete mágico, em que o funcionário embarca, arrebatando consigo a doce ou amarga invenção, que irá maravilhar outros individuos, igualmente prisioneiros de outras rotinas, por este vasto mundo de obrigações não escolhidas". A rotina e a quimera. Obra Completa. Rio de Janeiro, Companhia José Aguilar Editora, 1967, p. 671. 
brasileira, dos últimos trinta anos, está muito mais marcada pelos sucessos editoriais do que pelo aparecimento de obras significativas, em quase todos os campos, a não ser, talvez, no ensaio acadêmico, salvo pelas universidades, que permitiram a sobrevivência de um ponto de vista crítico e mais desprendido das exigências do mercado (embora nem sempre tenha sabido se proteger das atrações das modas do momento). As poucas obras literárias relevantes que surgiram nesse tempo foram, na maior parte, de autores formados pelo contexto anterior e que continuavam vivos e produzindo, como Carlos Drummond, Pedro Nava e João Cabral. O que passa a ocorrer então é o aparecimento de autores de um ou dois grandes sucessos de vendas, consumidos enquanto novidades, e uma sucessão de livros medíocres, particularmente nos gêneros do ensaio-reportagem, da biografia e do romance, competindo em vendagem algumas vezes com os livros de auto-ajuda, curiosidades e culinária. O ponto de vista da mercadoria emigrou das personagens e do processo histórico para a cabeça dos autores, e uma das pontes mais importantes desse trânsito foi um grupo de escritores, dentre eles, o mais importante talvez tenha sido Rubem Fonseca (sem entrar de modo algum no mérito literário da sua obra). Esse grupo procurou substituir a tradição literária européia, que tinha sido no Brasil, até então, a fonte principal de referência para o aprofundamento literário, pela mais comercial americana, a dos romances policiais, principalmente, com a expressão literária rebaixada para ser melhor aceita pelo leitor comum. Isso não se deu sem grande perda de memória, de compromissos sociais e éticos, de qualidade literária, argúcia crítica e investigativa, e experimentação estética. Primeiro, procurou-se "esquecer" grande parte das conquistas da tradição literária, inclusive das do país, e aproveitar-se apenas das que mais convinham para a criação do mercado de leitores; optou-se por vincular-se com os gêneros ou sub-gêneros literários que já haviam garantido sucessos comerciais na praça americana e européia, como o histórico-satírico, o policial e o auto biográfico, que explorava o grotesco, o thriller, a violência e o sexo. Isto não exclui que fosse também uma demanda da própria nova realidade social e institucional embrutecida e embrutecedora, gerada pela forma de desenvolvimento dos governos militares na década de 70 e continuada posteriormente. Porém, romper com a vertente crítica do passado literário garantia o descompromisso e a liberdade para explorar no novo mercado aqueles gêneros que já tinham sido testados em outros maiores. A busca da expansão do público leitor justificava o rebaixamento da qualidade e o 
abandono da visão crítica, o que facilitava também ao leitor o acesso à nova literatura. Criava-se um novo compromisso entre o autor e o leitor, promovido e intermediado pelas editoras e veículos culturais/comerciais, afinados com a indústria do entretenimento, tendo mais ou menos implícito que, para o leitor médio, bastava o escritor médio; para isso muitos autores se dispuseram ao próprio sacrifício e auto-mutilamento do espírito, adequando-se à situação, como se tudo devesse ser dado de imediato para quem buscava a distração e passar o tempo, sem ficar nada para segundas leituras e novas descobertas. A rasura impôs-se e se transformou em padrão do chamado livro descartável, aquele que não mais criava acervo, tradição e continuidade. E mudou o ritmo da leitura, ela ganhou velocidade e imediatez, o que significava que, de reflexiva, exigindo do leitor o máximo de atenção e sinceridade para o próprio reconhecimento, ela transformou-se em motivo de divertimento e esquecimento de si, enfim, num termo que tem sido muito pouco usado nos últimos tempos, alienante. E aqui o termo se emprega no sentido mais humanístico possível: deixar de se preocupar com o significado do humano e de se perguntar pelo sentido, para se passar sossegadamente ou ludicamente o tempo. Para isso abriram-se vários campos, como o místico, o histórico, o exótico populista nacional, e até a dura realidade das periferias e da violência policial. Faltou porém o autor voltar-se para si mesmo e olhar-se na sua metamorfose: ter-se tornado numa fonte de distração, como a luz que cega da televisão, com quem ele aprendeu fundamentalmente a esquecer e produzir esquecimento.

Não se quer dizer que não tenha havido autores que resistiram a isso; houve, mas a tendência é a de serem tratados marginalmente, principalmente quando não aceitam a confusão entre uma coisa e outra, quer dizer, o apelo comercial e a visão crítica do sujeito. Durante esse tempo, obras de efetivo valor literário foram vendidas como best-sellers, assim como obras encomendadas para serem bestsellers foram promovidas como sendo de alto valor literário; nem a crítica literária escapou desse processo, quantas vezes não se deixou usar, principalmente na forma de resenhas, como artigo de publicidade e vice-versa, quanto comentário sem nenhuma consistência não foi veiculado pelos grandes órgãos di imprensa travestidos de apreciações literárias abalizadas. Complementando una canção popular - que geralmente só diz metade da verdade - sobre un camelô que vendia 
"algodão por veludo", podemos perguntar: quanto veludo também não se vendeu por algodão nesse tempo. Só para citar um exemplo, a exacerbação do que foi dito anteriormente, e que valeria a pena um dia se estudar, foi o que se deu com a campanha de marketing que acompanhou o lançamento do livro do compositor Chico Buarque de Holanda, Estorvo, em 1991. Nela, tudo foi confundido com tudo, um livro de reconhecido valor crítico e expressivo, foi "vendido" como um produto qualquer de consumo; a crítica literária foi usada como material publicitário e vice-versa, eliminando as diferenças entre uma coisa e outra, e deformando as expectativas dos leitores desavisados e avisados, reduzidos todos a mercado consumidor. O poder que a mídia adquiriu sobre a opinião foi tão grande, que ela se permitiu estabelecer essa confusão, de tal modo que se acreditou que tudo poderia se transformar em tudo. Esse é um capítulo que a História Literária deveria um dia contar, se ela continuar existindo, nesse futuro sombrio que se anuncia.

Desse modo, por alienação, quer se entender aqui principalmente como a perda da memória, a destruição ou mistificação do passado, a rendição cínica ao dado, a satisfação conformista com o presente e a eliminação da crença na possibilidade de um futuro diferente. Se isso é uma tendência mundial, nas nações periféricas há um agravante, é a não existência de um colchão protetor de resistência civilizatória à corrente avassaladora do mercado, como o que possuem as nações avançadas, como as européias, a norte-americana e algumas orientais. É esse colchão que garante a memória às novas gerações, de modo a se formarem como homens também com outros parâmetros além do pobre presente, onde apoiarem as suas aspirações para o futuro. Faltam-nos ou foram muito enfraquecidos, com o recuo do Estado das funções públicas e redistributivas, como as educacionais e culturais, os poucos sistemas públicos civilizatórios que tínhamos, como um sistema escolar e universitário consistentes, uma rede ampla de bibliotecas e museus, uma política de conservação urbana e arquitetônica, a criação de teatros, salas de concerto, cine-clubes e praças públicas para encontros e espetáculos efetivamente culturais, com as respectivas companhias de representação e orquestras. Não possuímos esse mínimo de equipamento educacional e cultural que as sociedades burguesas européias conseguiram desenvolver e manter para se realizar um tipo de compensação ao poder corrosivo e nivelador da mercadoria, de modo a preservar o humano como um ser 
com memória e passado, capaz de lembrar e comparar os tempos, para não se perder no presente eterno das necessidades imediatas e materiais, como os novos bichos consumidores. Somente esse contato, possibilitado por tais instituições públicas, com o patrimônio cultural, literário e artístico, do passado e do presente, é que se poderia permitir a uma coletividade, reagindo a ele e procurando continuá-lo ou modificá-lo com novas realizações, formar ativamente alguma identidade, como a de um grupo maior do que a paróquia e o time de futebol, mas menor também do que a do cosmopolitismo abstrato e inespecífico, como o das etiquetas da moda e das grandes corporações, a bandeira da mercadoria, que, no Brasil, ameaçou transformar-se também na da literatura. Felizmente, também é preciso dizer, hoje, quando o processo da globalização mais se intensifica, a literatura começa a acordar e, o que é melhor, resistir, apesar de ainda nas catacumbas. É esse o desafio colocado hoje no plano da cultura para a sobrevivência da identidade nas nações periféricas, que, mais do que nunca, exige memória, esclarecimento e consciência crítica. 